\title{
Staff Nurses' Perception of the Hemodialysis Unit as Practice Environment and Patients' Perception of Nurse Caring Behaviors and their Level of Satisfaction
}

https://doi.org/10.37719/jhcs.2020.v2i1.oa001

\author{
JENEL S. KOON, MSN, RN1,2 \\ https://orcid.org/0000-0002-0667-3164
}

1VCEH Hemodialysis Center-Premier 101 Healthcare Management, Inc., Valenzuela City, Philippines 2University of the East Ramon Magsaysay Memorial Medical Center, Inc., Manila, Philippines

Corresponding author's email: koonj0135@uerm.edu.ph

\section{Abstract}

Background: Despite the concomitant rise of kidney diseases and hemodialysis services nationwide, the Philippines still lacks research on hemodialysis nursing care quality. Using nursing-sensitive indicators under the Nursing Role Effectiveness Model, this study aimed to describe hemodialysis nurses' perception of their unit as practice environment; patients' perception of nurse caring behaviors based on Jean Watson's 10 Caritas Processes; patients' level of satisfaction on nursing care; and determine the association between perceived nurse caring behaviors and satisfaction levels.

Methodology: This descriptive cross-sectional study purposely selected seven free-standing hemodialysis centers in Metro Manila. Ninety-four nurses were surveyed via complete enumeration using the Practice Environment Scale of Nursing Work Index (PES-NWI) while 345 randomly selected patients answered the Caring Factor Survey-Tagalog (CFS-T) and Patient Satisfaction of Nursing Care Quality Questionnaire-Tagalog (PSNCQQ-T). Pearson's correlation was used to analyze the gathered data.

Results: The study revealed that nurses perceived their respective work unit as a favorable practice environment while hemodialysis patients perceived nurse caring behaviors as practiced to a great extent and their satisfaction with nursing care as very good. The study also revealed a significant positive correlation between the process and outcome indicators $(r=0.64, p=<0.0001)$. 
Conclusion: The study reflected positive nursing-sensitive indicators in hemodialysis. However, hemodialysis facilities should improve nurse staffing, spiritual nurse caring behavior, and facilitate a more healing environment while maintaining their current favorable qualities.

Keywords: Hemodialysis nursing care quality, nursing-sensitive indicators, practice environment, nurse caring behaviors, patient satisfaction

\section{Introduction}

$\mathrm{H}$

emodialysis is the most common and preferred therapeutic approach for end-stage renal disease among most countries (United States Renal Data System [USRDS], 2016; Stavropoulou et al., 2017). In 2016, Philhealth (2017) reported hemodialysis as having the most filed health claims among procedures totaling up to more than 8 billion pesos, reflecting its substantial use among Filipinos. In hemodialysis, there is prolonged and repeated nurse-patient interaction, usually thrice weekly with four hours each session, throughout the patients' renal condition (Stavropoulou et al., 2017). This distinctively allows nurses to care for and positively impact their patients with chronic, and often debilitating, kidney disease. However, despite growing renal cases up to $15 \%$ annually and increasing numbers of hemodialysis facilities (Philippines News Agency [PNA], 2019), there are only select studies on hemodialysis nursing quality and its indicators (Thomas-Hawkins et al., 2008) and less so in the Philippines.

In 1996, the American Nurses Association (ANA) coined "nursing-sensitive indicators" (NSIs) based on Donabedian's Model of Quality Care (consisting of structure-process-outcome) to capture care and patient-related outcomes most affected by nursing care (Heslop \& Lu, 2014). In 1998, the Nursing Role Effectiveness Model (NREM) further described the nursing practice in relation to their healthcare roles, and linked patient outcomes to nurses' role functions as a way of examining nursing contribution within the healthcare system (Doran et al., 2002; Doran, 2002).

NREM identifies the structure as nurse, patient, and/or unit/environmental factors that influence the processes and outcomes of healthcare. Focusing on unit factors, these are practice setting variables that influence the nurses' ability to engage in effective role performance (Doran, 2002). The practice/work environment as structure indicator reflects organizational characteristics of a work setting that facilitate or constrain professional nursing practice (Lake \& Friese, 2006). There are a few numbers of research focused on the hemodialysis work environment compared to other specializations (Thomas-Hawkins et al., 2003; Burston et al., 2013) and results vary whether the hemodialysis unit is favorable (Thomas-Hawkins et al., 2003) or stressful and constraining (Ashker et al., 2012; Ross et al., 2009; Thomas-Hawkins et al., 2008). For this study, structure is defined as staff nurses' perception of the hemodialysis unit as practice environment. 
The next indicator, process, reflects nursing intervention and practice which impacts patient outcome (Heslop \& Lu, 2014). In NREM, process reflects what nurses do, with, or on behalf of patients that leads to health improvement under three distinct roles: the independent (autonomous nurse functions); interdependent (responsibilities shared with other healthcare team members); and dependent role (implementation of medical orders and treatments) (Doran, 2002). As hemodialysis nurses are endowed with much independent and autonomous functions essential to the unit-taking on flexible roles, having specialist knowledge, and often working with limited medical input that provides them an enhanced scope of practice (Gomez et al., 2011), this study defines process based on the independent role of hemodialysis nurses and this is measured using the 10 Caritas Processes.

Dr. Jean Watson's Theory of Human Caring postulates that nurse caring involves a range of knowledge, skills, and expertise that encompass holism, empathy, communication, clinical competence, technical proficiency, and interpersonal skills to potentiate therapeutic healing processes and relationships (Nelson \& Watson, 2011). These are substantiated into the 10 Caritas Processes or behaviors by which nurses in a caring role must be able to perform (Watson, 2006). In conjunction, NREM views the independent role as inherent to nursing care wherein nurses are held fully accountable and that nursing care holistically encompass physiological, physical, psychological, social, and spiritual aspects of health (Sidani et al., 2004). This study, therefore, sees process as an independent role and describes it as hemodialysis patients' perception of nurse caring behaviors based on the 10 Caritas Processes.

Lastly, NREM refers to outcomes as directly attributed to process or care interventions (Doran, 2002). To view if the nursing process has achieved merit, this study examines patient satisfaction, an indicator specifically associated with the independent nursing role (Irvine et al., 1998). Satisfaction refers to one's affective judgment rounded by his/her perceptions of quality (LaVela \& Gallan, 2014) and answers whether one's standards and level of contentment has been met (Devkaran, 2014). There have been differences in satisfaction among hemodialysis patients, for example, in Shnishil \& Mansour's (2013) work there was high satisfaction in clinical nursing care and nurse-patient relationship but moderate satisfaction in health education, meanwhile in Bayoumi and colleagues' (2016) study, there were unsatisfactory results and a need to improve nursing communication and interpersonal relationship with patients. Though satisfaction is expected to correlate positively to nurse caring behaviors (Nelson \& Watson, 2011), it is also possible to have high satisfaction despite negative experience and vice-versa (Devkaran, 2014) prompting this study to see if it occurs among hemodialysis patients as well. Aside from measuring patients' satisfaction with nursing care, this study also tests for correlation between the process and outcome indicators.

Nursing-sensitive indicators reflect healthcare delivery and patient outcomes and are helpful in quality improvement purposes (Heslop \& Lu, 2014; Burston et al., 2013). Due to fewer NSI use in hemodialysis versus other units (Burston et al., 2013) especially among Filipinos, use of NREM in hemodialysis also lacked relevant studies. Using NREM as framework, this study aims to contribute to the existing database by describing the hemodialysis practice environment, perceived nursing 
care, and patient satisfaction as reflectors of quality nursing care among selected hemodialysis facilities in Metro Manila.

\section{Methods}

\section{Study Design and Sample}

This study utilized a descriptive cross-sectional design to collect data across different hemodialysis centers at a given period. Only free-standing/outpatient centers were included to promote a homogenous population. The researcher conveniently invited 16 centers across Metro Manila but only seven centers all located in Quezon City consented to participate. Nurses with at least 3-month experience in hemodialysis who worked with patients daily, and were regularly paid employees were invited. This was to provide sufficiency of their experience in perceiving the unit as a practice environment, to limit variation in their caring abilities, and to consider the training period common among hemodialysis facilities. Three months of continuous hemodialysis care is also an acceptable cut-off period to delineate patient perception of nursing care and their level of satisfaction (Richardson et al., 2015). Complete enumeration of nurses was done to answer for the small population expected in each unit. Ninety-four out of 97 total nurses participated in the study with an attrition rate of $3.1 \%$.

For patient respondents, sampling size calculation was first done. Assuming $80 \%$ of patients who perceived above-average nurse caring behaviors had good satisfaction (Shnishil \& Mansour, 2013), and it is hypothesized that $65 \%$ of patients who perceived below-average nurse caring behavior had good satisfaction, with an alpha error of $5 \%$, effect size of $15 \%$, power of $90 \%$, and a one-tailed alternative hypothesis, the sample size required is 300 patients for two groups. Adding an attrition rate of $20 \%$, final sample size required 375 patients. Stratified random sampling with proportional allocation was then performed among the seven participating centers.

Hemodialysis patients were selected on the following criteria: at least 18 years old; with ESRD; has regular hemodialysis sessions from the same unit for the past three months; and hemodynamically stable and of good mental capacity/comprehension. Any instability requiring emergency care excluded potential respondents. The study also allowed patients who were elderly/seniors ( $\geq 60$ years old); terminally-ill; and/or those with physical disabilities who were willing and able to participate. To facilitate participation, the researcher allowed presence of an authorized representative/primary caregiver in the signing of consent; provided documents in large clear fonts; and allowed assistance from representative/caregiver or researcher in filling out forms given that patients fully made the answers. In the end, 345 patients out of 375 completed the study with an attrition rate of $8.0 \%$. 


\section{Instrumentation}

Nurse respondents answered the Practice Environment Scale of Nursing Work Index (PESNWI) which measured the quality of the nursing practice environment (Lake, 2002). It contained 31 items under five subscales, answerable in 10-15 minutes, and rated on a scale of 1 (strongly disagree) to 4 (strongly agree) indicating whether the descriptor was present in their current job. The presence of 4-5 subscales above a 2.5 rating indicated a favorable environment; 2-3 subscales with $>2.5$ indicated a mixed environment; and $\leq 1$ subscale with $>2.5$ indicated a poor/unfavorable environment (Lake \& Friese, 2006). Reliability analysis among Filipino nurses showed an acceptable Cronbach's a coefficient ( $\alpha=0.89$ ) (Barandino \& Soriano, 2019).

Patients answered the 10-item Caring Factor Survey by Dinapoli et al. (2010) (Tagalog version) or CFS-T to assess their perceptions of received nursing care as a loving consciousness towards them as a whole person (Persky et al., 2011a). Items were rated 1 (strongly disagree) to 7 (strongly agree) and the higher the score, the more evidence of care/caritas meaning that patients viewed the more caring nurses as those who had honored their individual wholeness and unity of mind-body-spirit (Persky et al., 2011b). Mean scores for the respondents were quantitatively interpreted as follows: (6.14-7.00) very great extent; (5.28-6.13) great extent; (4.41-5.27) above average extent; (3.54-4.40) average extent; (2.67-3.53) below average extent; (1.81-2.66) low extent; and (0.94-1.80) very low extent that the Caritas Process was used by the nurse. The tool yielded a reliable Cronbach's alpha of 0.85 .

Patients also answered the Patient Satisfaction with Nursing Care Quality Questionnaire (PSNCQQ) by Laschinger and colleagues (2005) (Tagalog version) or PSNCQQ-T. This contained 19 main items which measured patient satisfaction with nursing care, plus 4 additional questions for overall care, well-being, and intent to recommend. The items were answered in 10-15 minutes and rated 1 (poor) to 5 (excellent). Scores for the main items were averaged to yield a single value for each respondent. Reliability analysis showed equally high reliability of $\alpha=0.96$.

To facilitate comprehension of patients, the Commission on the Filipino Language or "Komisyon sa Wikang Filipino" (KWF) which is the official regulating body of the Filipino language for developing, preserving, and promoting the local language (Komisyon sa Wikang Filipino, 1991) was approached for Tagalog translation of patient questionnaires resulting to the CFS-T and PSNCQQ-T versions. Internal pilot test of both tools among 30 hemodialysis patients showed that translation was clear and could be easily understood by the participants.

\section{Data Collection Procedures}

Prior to implementation, the study underwent panel review; obtained permission to use the instruments from their corresponding authors, and secured an ethics approval (RIHS ERC Code: 0590/E/G/18/101). The researcher also secured written approval from the hemodialysis centers' 
medical director and/or nurse managers in accordance to their unit protocol. As permitted, the researcher conducted poster/flyer dissemination and a face-to-face invitation of patients which included screening of their eligibility. During implementation, the researcher fully explained the consent and data collection procedures to eligible participants following the guidelines stated above. For nurses, tools were provided at the start of shift which was submitted any time before their shift ends. For patients, tools were provided at their own convenience or time preference (between middialysis or after hemodialysis in the unit's lobby or designated area). Anonymity and confidentiality were maintained for both groups. The study gifted tokens (free pen and socks) for complete participation.

\section{Data Analysis}

Collected data were initially entered into Microsoft Excel for descriptive analysis and presentation. For statistical analysis, Pearson's correlation coefficient tested for the magnitude and direction of association between the process and outcome indicators using the tallied means. Data was computed using IBM SPSS Statistics for Windows, Version 20.0. Armonk, NY: IBM Corp.

\section{Result}

\section{Demographic Profiles}

A majority of hemodialysis nurses were young ( $\leq 30$ years old) $(58.5 \%)$, female $(70.2 \%)$ and single (80.9\%) during data collection. Nearly $90 \%$ had certification in BLS and ACLS, but only $14.9 \%$ were Certified Nephrology Nurses. Most had formal hemodialysis training (95.7\%). The average length of experience hemodialysis nurses had in their current unit was a little over two years, similar with their total length of experience as hemodialysis nurses (Table 1).

Table 1. Demographic profile of Hemodialysis Nurses $(n=94)$

\begin{tabular}{llc}
\hline \multicolumn{2}{c}{ Demographic Profiles } & $\begin{array}{c}\text { Nurses } \\
\mathbf{n}(\%)\end{array}$ \\
\hline Gender & Male & \\
& Female & $27(28.7)$ \\
Age & & $66(70.2)$ \\
Civil Status & \\
$\quad$ Single & $29.59(4.25)$ \\
& Married & \\
& Living with common-law partner & $76(80.9)$ \\
Educational Attainment & $17(18.1)$ \\
Bachelor's Degree & $1(1.1)$ \\
Master's Degree & $92(97.9)$ \\
&
\end{tabular}




\section{Demographic Profiles}

\section{Certification*}

Basic Life Support (BLS) and

Cardiopulmonary Resuscitation (CPR)

Advanced Cardiac Life Support (ACLS)

Pediatric Advanced Life Support (PALS)

Intravenous Therapy (IVT)

Certified Nephrology Nurse - from Renal

Nurses Association of the Philippines (RENAP)

With formal hemodialysis training with units/certification

Yes

Length of training

$\leq 1$ month

1 mo. 1 day -3 mo.

$>3 \mathrm{mo}$.

No answer

No

Length of experience in current hemodialysis unit (in months)

Mean (SD)

Total length of experience as hemodialysis nurse (in months)

$\frac{\text { Mean (SD) }}{{ }^{*} \text { multiple response items }}$

\section{Nurses}

$\mathrm{n}(\%)$

$83(88.3)$

$84(89.4)$

$2(2.1)$

$73(77.7)$

$14(14.9)$

90 (95.7)

$15(16.7)$

$56(62.2)$

$11(12.2)$

$8(8.9)$

$4(4.3)$

$25.1(22.3)$

$31.9(25.0)$

For hemodialysis patients, they were mostly middle-aged (41-50 years old) $(26.4 \%)$ married $(61.6 \%)$ men $(56.5 \%)$ who graduated with a Bachelor's degree $(47.2 \%)$ and were unemployed during data collection (69.9\%). 40\% of patients have been having hemodialysis for the past 1-3 years, with $61.2 \%$ having twice weekly sessions. Co-morbid hypertension (69.6\%) was also evident, followed by diabetes (35.7\%). Vision difficulties and ambulation problems were, likewise, reported $(35.1 \%$ and $32.5 \%$, respectively), and $51.3 \%$ had some form of assistance with answering the survey.

Table 2. Demographic profile of Hemodialysis Patients $(n=345)$

\begin{tabular}{llc}
\hline \multicolumn{1}{c}{ Demographic Profiles } & $\begin{array}{c}\text { Patients } \\
\mathbf{n}(\%)\end{array}$ \\
\hline Gender & Male & $195(56.5)$ \\
& Female & $150(43.5)$ \\
Age & Mean (SD) & \\
Civil Status & Single & $49.87(13.17)$ \\
& Married & \\
& Living with common-law partner & $83(24.1)$ \\
& Widowed & $209(60.6)$ \\
& & $14(4.1)$ \\
\end{tabular}




\begin{tabular}{|c|c|}
\hline Demographic Profiles & $\begin{array}{c}\text { Patients } \\
\mathrm{n}(\%)\end{array}$ \\
\hline Separated/Annulled & $8(2.3)$ \\
\hline $\begin{array}{l}\text { Employment Status } \\
\text { Working } \\
\text { Non-working }\end{array}$ & $\begin{array}{l}103(29.9) \\
241(69.9)\end{array}$ \\
\hline $\begin{array}{l}\text { Educational Attainment } \\
\text { Did not finish primary school } \\
\text { Primary education } \\
\text { Secondary education } \\
\text { Bachelor's Degree } \\
\text { Postgraduate } \\
\text { Technical/Vocational }\end{array}$ & $\begin{array}{c}3(0.9) \\
27(7.8) \\
123(35.7) \\
163(47.2) \\
13(3.8) \\
15(4.3)\end{array}$ \\
\hline $\begin{array}{l}\text { Co-morbidities* } \\
\text { Hypertension } \\
\text { Diabetes } \\
\text { Heart disease } \\
\text { Lung disease } \\
\text { History of stroke } \\
\text { Cancer } \\
\text { Hepatitis B } \\
\text { Hepatitis C }\end{array}$ & $\begin{array}{c}240(69.6) \\
123(35.7) \\
76(22.0) \\
6(1.7) \\
38(11.0) \\
4(1.2) \\
12(3.5) \\
4(1.2)\end{array}$ \\
\hline $\begin{array}{l}\text { Duration of hemodialysis experience in current hemodialysis } \\
\text { unit } \\
\qquad \begin{array}{l}<12 \mathrm{mo} . \\
12-36 \mathrm{mo} . \\
36-60 \mathrm{mo} . \\
>60 \mathrm{mo} . \\
\text { No answer }\end{array}\end{array}$ & $\begin{array}{c}91(26.4) \\
138(40.0) \\
49(14.2) \\
62(18.0) \\
5(1.4)\end{array}$ \\
\hline $\begin{array}{l}\text { Hemodialysis frequency per week } \\
\text { Once (including alternate once-twice) } \\
\text { Twice (including alternate twice-thrice) } \\
\text { Thrice } \\
\text { No answer }\end{array}$ & $\begin{array}{c}4(1.2) \\
211(61.2) \\
128(37.1) \\
2(0.5)\end{array}$ \\
\hline $\begin{array}{l}\text { Difficulty/ies* } \\
\text { Hearing } \\
\text { Sight } \\
\text { Memory } \\
\text { Walking/ambulation } \\
\text { Others (i.e. breathing, cramps, joint pain, speech) }\end{array}$ & $\begin{array}{c}20(5.8) \\
121(35.1) \\
48(13.9) \\
112(32.5) \\
8(2.3)\end{array}$ \\
\hline
\end{tabular}

*multiple response items

\section{Structure: Staff Nurses' Perception of the Hemodialysis Unit as Practice Environment}

Overall, hemodialysis nurses reported their units as favorable environments $(93.6 \%)$ or facilitative to their practice of quality nursing. Among the five subscales found in a workplace (Table $3)$, the subscale nurse-physician relations were rated highest $(M=3.45)$ which involved a positive working relationship, teamwork, and collaboration among nurses and physicians. On the other hand, 
the lowest subscale was staffing and resource adequacy $(M=2.97)$ wherein, out of all 31 items, nurses also rated the lowest having enough $R$ Ns to provide quality patient care $(M=2.84)$.

Table 3. Structure Indicator: Qualities Present in a Hemodialysis Unit as Perceived by Hemodialysis Nurses

\begin{tabular}{clc}
\hline Subscale & \multicolumn{1}{c}{ Structure: Practice Environment Characteristic/Quality } & Mean \pm SD \\
\hline 1 & Nurse participation in dialysis provider affairs & $3.22 \pm 0.60$ \\
2 & Nursing foundations for quality of care & $3.27 \pm 0.64$ \\
3 & Nurse manager ability, leadership and support of nurses & $3.38 \pm 0.62$ \\
4 & Staffing and resource adequacy & $2.97 \pm 0.71$ \\
5 & Collegial nurse-physician relations & $3.45 \pm 0.57$ \\
\hline
\end{tabular}

\section{Process: Hemodialysis Patients' Perception of Nurse Caring Behaviors}

Using Watson's Theory of Human Caring as the basis for nurse caring behaviors, overall patient perception of the 10 Caritas Processes has been rated to a great extent $(M=5.80)$, with majority rating so $(46.7 \%)$ and only $0.3 \%$ having very low perception. The patients also had high appreciation for their nurses' loving-kindness $(M=6.29)$ but had diminished recognition of nurses' spiritual care $(\mathrm{M}=4.78)$ (Table 4).

\section{Outcome: Hemodialysis Patients' Level of Satisfaction with Nursing Care}

Patients were satisfied with the nursing services provided ( $M=3.83$ ) where $50.4 \%$ had very good levels and only $2.9 \%$ had fair to poor satisfaction scores. Out of the 19 items they were most satisfied with hemodialysis nurses' caring attitudes $(M=4.1)$ but least pleased with the presence of a quiet and restful atmosphere in the unit $(M=3.56)$ (Table 4).

Table 4. Results for Process and Outcome Indicators

\begin{tabular}{|c|c|c|}
\hline & Mean $\pm S D$ & Interpretation \\
\hline $\begin{array}{l}\text { Process: Overall patients' perception of nurse caring behaviors } \\
\text { based on the } 10 \text { Caritas Processes }\end{array}$ & $5.80 \pm 1.25$ & Great extent \\
\hline $\begin{array}{l}\text { Highest: Everyday that I am here, care is provided with } \\
\text { loving kindness }\end{array}$ & $6.29 \pm 0.87$ & $\begin{array}{l}\text { Very great } \\
\text { extent }\end{array}$ \\
\hline 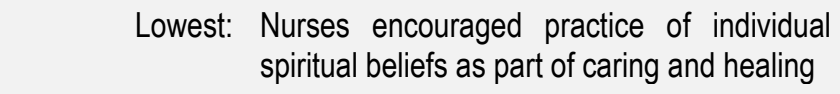 & $4.78 \pm 1.60$ & $\begin{array}{l}\text { Above average } \\
\text { extent }\end{array}$ \\
\hline Outcome: Overall patient satisfaction with nursing care & $3.83 \pm 0.92$ & Very good \\
\hline Highest: Concern and caring attitudes by nurses & $4.1 \pm 0.84$ & Very good \\
\hline Lowest: Restful atmosphere provided by nurses & $3.56 \pm 0.92$ & Very good \\
\hline
\end{tabular}




\section{Process and Outcome: Correlation between Patient Perception of Nurse Caring Behaviors and their Levels of Satisfaction}

Statistical analysis utilized Pearson's correlation to test for the magnitude and direction of association between the process and outcome indicators. The product showed a strong, positive correlation between the two $(r=0.64)$ indicating that as patient perception of nurse caring behaviors increases or improves, their level of satisfaction increases proportionately; and this is statistically significant $(p=<0.0001)$ (Table 5).

Table 5. Relationship between Process (Perceived Nurse Caring Behaviors) and Outcome (Patient Satisfaction with Nursing Care)

\begin{tabular}{ccc}
\hline$r$ Coefficient & $p$ Value & Interpretation \\
\hline 0.6438 & $<0.0001$ & Significant \\
\hline
\end{tabular}

${ }^{*} p$ value is significant at 0.05 level

\begin{tabular}{|c|c|c|}
\hline $\begin{array}{l}\text { Structure } \\
\text { Unit/Environmental Structure } \\
\quad \text { Indicator } \\
\text { Hemodialysis Unit Practice } \\
\text { Environment Subscales: } \\
\text { - } \quad \text { Nurse participation in unit } \\
\text { affairs } \\
\text { - } \quad \text { Nursing foundations for } \\
\text { quality of care } \\
\text { - Nurse manager ability, } \\
\text { leadership and support of } \\
\text { nurses } \\
\text { - Staffing and resource } \\
\text { adequacy } \\
\text { Collegial nurse-physician } \\
\text { relations } \\
\text { Nurses' Perception: } \\
\text { - Favourable ( } \geq 4 \\
\text { subscales exceed rating } \\
\text { of 2.5) }\end{array}$ & $\begin{array}{l}\text { Process } \\
\text { Independent Nursing Role } \\
\text { 10 Carative Factors/ Caritas } \\
\text { Processes: } \\
\text { - } \quad \text { Practicing loving kindness } \\
\text { - } \quad \text { Decision-making } \\
\text { - } \quad \text { Instilling faith and hope } \\
\text { - } \quad \text { Teaching and learning } \\
\text { - } \quad \text { Spiritual beliefs and } \\
\text { - } \quad \text { Hoclistic care } \\
\text { - } \quad \text { Helping and trusting } \\
\text { - } \quad \text { relationship } \\
\text { - } \quad \text { Promoling environment } \\
\text { - } \quad \text { feelings expression of } \\
\text { Miracles } \\
\text { Patients' Perception: } \\
\text { - } \quad \text { Great extent }\end{array}$ & $\begin{array}{l}\text { Outcome } \\
\text { Patient Satisfaction } \\
\text { Patient Satisfaction } \\
\text { with Nursing Care: } \\
\text { - Very good }\end{array}$ \\
\hline
\end{tabular}

Figure 1. Framework used in this study and their results

\section{Discussion}

The goal of this study was to gain an understanding of the quality of hemodialysis nursing, a fast-growing healthcare service in the Philippines and worldwide, by describing its quality indicators sensitive to nursing. The findings showed that hemodialysis nurses perceived their units as favorable 
practice environments with at least four organizational qualities that provide a favorable workplace and facilitate quality nursing practice. The results deviate but not fully negate prior research where the hemodialysis unit was found stressful and intense (Ashker et al., 2012; Ross et al., 2009). A good work perception among nurses continues to be important due to its association with positive job experiences, fewer concerns with quality of care, better intention to stay, lower burnout levels, and significantly lower patient mortality and rescue rates (Gardner et al., 2007; Aiken et al., 2008).

Comparing the environment subscales, collegial nurse-physician relations with the highest score reflects a professional practice environment consistent with previous findings (Gardner et al., 2007; Thomas-Hawkins et al., 2003). On the contrary, staffing and resource adequacy with the lowest score mirrors the findings of Barandino and Soriano (2019) contributing to workload stress and acting as the first cause of nurses' negative perceptions of the hemodialysis work environment (ThomasHawkins et al., 2003, 2008). Assuming all hemodialysis units followed the prescribed 1 nurse-to-4 patient ratio $(\mathrm{DOH}, 2012)$, nurses still perceived a lack of staffing. Staffing problems and a heavy workload can lead to task-oriented care, nurse-perceived low-quality care, decreased job satisfaction (Hayes et al., 2015), and increase nurses' intent to leave their jobs (Gardner et al., 2007).

For the process indicator, most hemodialysis patients perceived nurses' caring behavior (based on the 10 Caritas Processes) to a great extent meaning that nurses had a profound engagement with patients and cared for them as a whole, including their physical, mental, and spiritual needs. This may be because in general nurses aim to provide quality care through compassionate service, value of life, and commitment to other people regardless of status (Anquillano-Carsola \& Castro-Palaganas, 2016). Nurses' care and inclusion of patients' spiritual beliefs as part of healing, however, was the lowest-rated behavior partly due to its lack of clear definition and applicability to some patients. Patients may also interpret not receiving or noticing components that might have been considered as spiritual care (Leger et al., 2012). Regardless, spiritual care warrants nurses' greater attention as this has been effective among hemodialysis patients to overcome depression, anxiety, and stress (Musa et al., 2017). Consistent with Watson's Theory of Human Caring and inherent in the NREM independent nursing role, hemodialysis nurses must work toward the ability of incorporating holistic care with technical and clinical proficiencygoing beyond tasks and nursing routine and caring for the whole person, including their spiritual health.

Majority of patients also had very good satisfaction ratings with received nursing care, similar to the findings of Ferentinou and colleagues' (2016) and Calong Calong and Soriano (2018). This implies that nursing care provided among the participating hemodialysis centers were able to meet patients' standards, expectations, and level of contentment. Individually, all items received very good satisfaction scores; however, provision of a restful atmosphere by nurses scored the lowest which may be influenced by conversations of surrounding nurses and/or primary caregivers and by the uninterrupted use of television or music players common among hemodialysis units. The focus must then be given as excessive noise can prevent patients' needed sleep or rest, impair detection of 
patient and hemodialysis machine problems, and compromise communication among nurses (Prestes et al., 2015).

Statistical analysis displayed a significant positive correlation between process and outcome indicators, meaning that as patient perception of nurse caring behaviors increases, their level of satisfaction increases proportionately. This echoes Nelson and Watson's (2011) expectation of patient satisfaction associating positively with nurse caring perception, and with Palmer's crosscountry evaluation (2014) where better dialysis care performance scores were associated with higher overall patient satisfaction. Devkaran (2014) stated, however, that a high satisfaction score may not always follow a positive experience or objective quality care, and vice-versa. When the study's process and outcome responses were grouped into excellent, good, and poor categories, three patients had poor perception of nurse caring behaviors but still had a good level of satisfaction. This deviance, although possible, is trivial in comparison to the rest of the findings.

The study also noted some limitations. First, the use of a mixed method instead of quantitative design may explain better the full range of feelings, values, and experiences with hemodialysis care. Second, the study did not test the association between structure and process/outcome indicators due to different participants groups where patients were not paired with nurses and instead responded based on the overall nursing care received. Third, this study did not test causal sequences as to how the outcomes were produced; hence, another design and statistics are needed to establish such facts. Lastly, patient-reported experiences and satisfaction measures may be limited as there is tendency to report approval of services due to acquiescence or social desirability bias that may result in false-high scores (Pearson et al., 1989). To minimize this, the study maintained anonymity and confidentiality of responses and respected patient preferences on how they wished to answer. Likewise, the researcher bore no involvement with any of the facilities nor partiality to the collected data. Researchers may consider these limitations in pursuing future studies surrounding hemodialysis nursing care quality.

\section{Conclusion}

The study reflected positive nursing-sensitive indicators in hemodialysis. Hemodialysis facilities have good and facilitative practice environments, and hemodialysis patients perceived nurses as caring and were satisfied with the care they received. However, improvements can still be made. It may be beneficial to address staffing needs in hemodialysis units, to consider the physical aspects of care such as promoting a restful atmosphere for patients and to expand nurses' abilities in providing spiritual care. Facility administrators and nurse managers play both active and supportive roles in the improvement of these areas. 


\section{Conflict of Interest}

The author have no conflict of interest to disclose.

\section{Acknowledgement}

The author would like to express her sincerest gratitude to Dr. Jonathan Cura for his guidance, wisdom, and encouragement. Special thanks also to the hemodialysis facilities for their participation in the study, and to Mr. Johnny Koon for his full active support.

\section{References}

Aiken, L. H., Clarke, S. P., Sloane, D. M., Lake, E. T., \& Cheney, T. (2008). Effects of hospital care environment on patient mortality and nurse outcomes. Journal of Nursing Administration, 38(5), 223-229. https://doi.org/10.1097/01.NNA.0000312773.42352.d7

Anquillano-Carsola, F., \& Castro-Palaganas, E. (2016). Nursing, nightingale and beyond: Voices, dialogues and talks of the future. Philippine Journal of Nursing, 2(2), 11-23.

Ashker, V. E., Penprase, B., \& Salman, A. (2012). Work-related emotional stressors and coping strategies that affect the well-being of nurses working in hemodialysis units. Journal of Nephrology Nursing, 39(3), 231-236.

Barandino, J. P. \& Soriano, G. (2019). Practice environment and work-related quality of life among nurses in a selected hospital in Zamboanga, Philippines: A correlational study. Nursing Practice Today, 6(4), 223-228. https://doi.org/10.18502/10.18502/npt.v6i4.1944

Bayoumi, M., Hoda, A., Guindy, E., \& Ahmed, A. (2016). Patients' satisfaction with care at dialysis unit. International Journal of Nursing Science, 6(5), 117-122. https://doi.org/10.5923/j.nursing.20160605.02

Burston, S., Chaboyer, W., \& Gillespie, B. (2013). Nurse-sensitive indicators suitable to reflect nursing care quality: A review and discussion of issues. Journal of Clinical Nursing, 23(13-14), 269-273. https://doi.org/10.1111/jocn.12337

Calong Calong, K. \& Soriano, G. (2018). Caring Behavior and Patient Satisfaction: Merging for Satisfaction. International Journal of Caring Sciences, 11(2), 697-703

Devkaran, S. (2014). Patient experience is not patient satisfaction: Understanding the fundamental differences. $\mathrm{https}$ :/www.google.com/url?sa=t\&rct=j\&q=\&esrc=s\&source=web\&cd=1\&cad=rja\&uact=8\&ved=0ah UKEwiC9te6urfZAhWFS7wKHUaYCSYQFggoMAA\&url=https\%3A\%2F\%2Fisqua.org\%2Fdocs\%2F default-source\%2Feducation-\%2Fisqua-webinar_november-2014_subashnie-devkaran.pdf\%3F sfvrsn\%3D0\&

DiNapoli, P., Nelson, J., Turkel, M., \& Watson, J. (2010). Measuring the caritas processes: Caring Factor Survey. International Journal for Human Caring, 14(3), 15-20.

Doran, D. I. (2002). Development of the Nursing Role Effectiveness Model. Retrieved from Nursing Role Effectiveness Model: Conceptualizing to theory testing: http://stti.confex.com/stti/sos13/techprogram /paper_11238.htm 
Doran, D., Sidani, S., Keatings, M., \& Doidge, D. (2002). An empirical test of the Nursing Role Effectiveness Model. Journal of Advanced Nursing, 38(1), 29-39. https://doi.org/10.1046/j.1365-2648.2002.02143.x

Ferentinou, E., Giannakopoulou, M., Prezerakos, P., Sachlas, A., Theofilou, P., \& Zyga, S. (2016). Measuring beliefs and satisfaction regarding nursing care among Greek patients on hemodialysis. Journal on Behavioral Health, 5, 117-122.

Gardner, J. K., Thomas-Hawkins, C., Fogg, L., \& Latham, C. E. (2007). The relationships between nurses' perceptions of the hemodialysis unit work environment and nurse turnover, patient satisfaction, and hospitalizations. Journal of Nephrology Nursing, 34(3), 271-281.

Gomez, N. J., Castner, D., \& Dennison, H. A. (2011). Incorporating the nephrology nursing scope and standards of practice into clinical practice. Journal of Nephrology Nursing, 311-317.

Hayes, B., Bonner, A., \& Douglas, C. (2015). Haemodialysis work environment contributors to job satisfaction and stress: A sequential mixed methods study. BioMed Central, 14(58), 1-13. https://doi.org/10.1186/s12912-015-0110-x

Heslop, L., \& Lu, S. (2014). Nursing-sensitive indicators: A concept analysis. Journal of Advanced Nursing, 70(11), 2469-2482. https://doi.org/10.1111/jan.12503

Irvine, D., Sidani, S., \& Hall, L. M. (1998). Linking outcomes to nurses' roles in health care. Nursing Economics, 16(2), 58-64.

Komisyon sa Wikang Filipino. (1991). Tungkol sa KWF. http://kwf.gov.ph/tungkol-sa-kwf/

Lake, E. T. (2002). Development of the Practice Environment Scale of the Nursing Work Index. Research in Nursring \& Health, 25, 176-188. https://doi.org/10.1002/nur.10032

Lake, E. T., \& Friese, C. R. (2006). Variations in nursing practice environments. Nursing Research, 55(1), 1-9. https://doi.org/10.1097/00006199-200601000-00001

Lashinger, H., McGillis Hall, L., Pedersen, C., \& Almost, J. (2005). A psychometric analysis of the Patient Satisfaction with Nursing Care Quality Questionnaire: An actionable approach to measuring patient satisfaction. Journal of Nursing Care Quality, 20(3), 220-230. https://doi.org/10.1097/00001786200507000-00006

LaVela, S., \& Gallan, A. (2014). Evaluation and measurement of patient experience. Patient Experience Journal, 1(1), 28-36. https://doi.org/10.35680/2372-0247.1003

Leger, P., Sramek, D., Conklin, S., \& Nelson, J. (2012). Patient and nurse perception of the individual caring relationship. In J. Nelson, \& J. Watson, Measuring caring: International research on caritas as healing (pp. 87-96). Springer Publishing Company.

Musa, A. S., Pevalin, D. J., \& Khalaileh, M. A. (2017). Spiritual well-being, depression, and stress among hemodialysis patients in Jordan. Journal of Holistic Nursing, 36(4), 354-365. https://doi.org/10.1177/0898010117736686

Nelson, J., \& Watson, J. (2011). Measuring caring: International research on caritas as healing. Springer Publishing Company.

Palmer, S., de Berardis, G., Craig, J., Tong, A., Tonelli, M., Pellegrini, F., Ruospo, M., Hegbrant, J., Wollheim, C., Celia, E., Gelfman, R., Ferrari, J., Torok, M., Murgo, M., Leal, M., Bednarek-Skublewska, A., Dulawa, J., \& Strippoli, G. (2014). Patient satisfaction with in-centre haemodialysis care: An international survey. British Medical Journal Open, 4(5). https://doi.org/10.1136/bmjopen-2014005020

Pearson, A., Durant, I., \& Punton, S. (1989). Determining quality in a unit where nursing is the primary intervention. Journal of Advanced Nursing, 14(4), 269-273. https://doi.org/10.1111/j.13652648.1989.tb03413.x 
Persky, G., Felgen, J., \& Nelson, J. (2011a). Measuring caring in primary nursing. In J. Nelson, \& J. Watson, Measuring caring. Springer Publishing Company, LLC.

Persky, G., Nelson, J., Watson, J., \& Bent, K. (2011b). Profile of a nurse effective in caring. In J. Nelson, \& J. Watson, Measuring caring: International research on caritas as healing. Springer Publishing Company, LLC.

PhilHealth. (2017). 2016 Stats \& Charts. https://www.philhealth.gov.ph/about_us/statsncharts/snc2016.pdf

Philippines News Agency. (2019). ARQCapital boosts bid to set up more dialysis centers in PH. https://www.pna.gov.ph/articles/1086669

Prestes, F., Beck, C., Magnago, T., da Silva, R., \& Tavares, J. (2015). Working context in a hemodialysis service: Evaluation of nursing staff. Text Context Nursing, 24(3), 637-645. https://doi.org/10.1590/0104-07072015000220014

Richardson, M., Paine, S., Grobert, M., Stidley, C., Gabbay, E., Harford, A., Zager, P., Miskulin, D., Meyer, K. (2015). Satisfaction with care of patients on hemodialysis. Cinical Journal of the American Society of Nephrology, 10(8), 1428-1434. https://doi.org/10.2215/CJIN.11241114

Ross, J., Jones, J., Callaghan, P., Eales, S., \& Ashman, N. (2009). A survey of stress, job satisfaction and burnout among hemodialysis staff. Journal of Renal Care, 35(3), 127-133. https://doi.org/10.1111/j.1755-6686.2009.00102.x

Shnishil, A. T., \& Mansour, K. A. (2013). Assessment of patients' satisfaction toward nursing care at hemodialysis units. Iraqi National Journal of Nursing Specialties, 26(1), 1-9.

Sidani, S., Doran, D., \& Mitchell, P. (2004). A theory-driven approach to evaluating quality of nursing care. Journal of Nursing Scholarship, 36(1), 60-65. https://doi.org/10.1111/j.1547-5069.2004.04014.x

Stavropoulou, A., Grammatikopoulou, M., Rovithis, M., Kyriakidi, K., Pylarinou, A., \& Markaki, A. (2017). Through the patients' eyes: The experience of end-stage renal disease patients concerning the provided nursing care. MDPI - Healthcare, 5(36), 1-11. https://doi.org/10.3390/healthcare5030036

Thomas-Hawkins, C., Denno, M., Currier, H., \& Wick, G. (2003). Staff nurses' perceptions of the work environment in freestanding hemodialysis facilities. Nephrology Nursing Journal, 3(2), 169-178.

Thomas-Hawkins, C., Flynn, L., \& Clarke, S. (2008). Relationships between registered nurse staffing, processes of nursing care, and nurse-reported patient outcomes in chronic hemodialysis units. Journal of Nephrology Nursing, 35(2), 123-131.

United States Renal Data System. (2016). Chapter 13: International comparisons. https://www.usrds.org/2016 /view/v2_13.aspx

Watson, J. (2006). Caring Theory as an ethical guide to administrative and clinical practices. Nursing Administration Quarterly, 30(1), 48-55. https://doi.org/10.1097/00006216-200601000-00008

\section{About the Author}

Jenel S. Koon, MSN, RN, obtained her Bachelor of Science in Nursing degree from Our Lady of Fatima University-Valenzuela. While working full-time as a hemodialysis nurse in Valenzuela City Emergency Hospital, she continued her Master of Science in Nursing from University of the East Ramon Magsaysay Memorial Medical Center, Inc., during which she presented her study at the PNRSI $12^{\text {th }}$ National Nursing Research Conference. Her interests include nurse caring as a philosophy, hemodialysis nursing, and forensic science. Fascinated by research, she has also previously done part-time work as a research assistant. 